\title{
High-Dose, Extended-Interval Gentamicin and Tobramycin for Pediatric Inpatients: A Survey of Canadian Hospital Pharmacists
}

\author{
Caitlin Roy, Carolyn Gray, Lisa Ruda, Ali Bell, and Jennifer Bolt
}

\begin{abstract}
Background: The use of high-dose, extended-interval aminoglycosides, a common practice in adult populations, is less well established for pediatric patients. In younger populations, these drugs are often administered according to a multiple daily dosing method.

Objective: To characterize prescribing practices for aminoglycosides in pediatric inpatients across Canada, with a focus on high-dose, extendedinterval regimens.
\end{abstract}

Methods: This study was based on an electronic survey of pharmacists representing Canadian health care delivery organizations that provided pediatric inpatient services, which was distributed in March 2015. Questions focused on demographic characteristics; indications for highdose, extended-interval tobramycin or gentamicin; use of these regimens in patients with particular comorbidities; empiric dosing; monitoring parameters; and the extent of pharmacists' authority to independently prescribe doses and order monitoring parameters for aminoglycosides at their respective institutions.

Results: Forty-five (48\%) of the 94 prospective participants responded to the survey. Of these 45 respondents, 35 (78\%) indicated that their respective health regions used high-dose, extended-interval tobramycin or gentamicin in pediatric inpatients. The patient characteristics for use of such regimens were varied. The median reported doses were $10 \mathrm{mg} / \mathrm{kg}$ for pulmonary exacerbation in cystic fibrosis, $7 \mathrm{mg} / \mathrm{kg}$ for urinary tract infection, and $8 \mathrm{mg} / \mathrm{kg}$ for febrile neutropenia. Thirty-one (89\%) of the 35 respondents using these regimens reported that they monitored serum levels, and 27 (77\%) reported monitoring for nephrotoxicity. With regard to prescriptive authority, 7 (16\%) of the 45 respondents indicated that pharmacists were authorized to independently adjust dosing at their institutions, and pharmacists at $14(31 \%)$ of 45 sites were authorized to order monitoring parameters.

Conclusions: High-dose, extended-interval aminoglycoside therapy was frequently used for pediatric patients across Canada, although the dosages and monitoring practices varied greatly. The information from this study can be used for cross-comparison of practice by other centres across Canada.

Keywords: pediatrics; aminoglycosides; gentamicin; tobramycin; highdose, extended-interval therapy

\section{RÉSUMÉ}

Contexte : L'utilisation de doses élevées d'aminosides administrées à intervalle prolongé est une pratique répandue chez l'adulte, mais moins bien établie chez l'enfant. Dans les populations plus jeunes, ces médicaments sont souvent donnés selon une méthode d'administration multiquotidienne.

Objectif : Offrir un portrait des habitudes de prescription d'aminosides chez des enfants hospitalisés à l'échelle du Canada en accordant une attention aux schémas posologiques avec administration d'une dose élevée à intervalle prolongé.

Méthodes : La présente étude s'appuie sur une enquête électronique réalisée en mars 2015 auprès de pharmaciens représentant des organismes canadiens de prestation de soins de santé qui offrent des services d'hospitalisation pour les enfants. Les questions portaient sur : les caractéristiques démographiques; les indications pour les doses élevées à intervalle posologique prolongé de gentamicine ou de tobramycine; l'emploi de ces schémas chez les patients atteints de certaines comorbidités; les posologies empiriques; les paramètres de surveillance; et l'étendue du droit que détiennent les pharmaciens de prescrire les doses d'aminosides de façon indépendante et les paramètres de surveillance connexes dans leurs établissements respectifs.

Résultats : Quarante-cinq (48\%) des 94 potentiels participants ont répondu au sondage. Parmi les 45 répondants, 35 (78 \%) ont indiqué que leur régie régionale de la santé faisait l'emploi de schémas avec administration d'une dose élevée à intervalle prolongé de tobramycine ou de gentamicine chez des enfants hospitalisés. Les caractéristiques des patients pour l'utilisation de tels schémas variaient. Les doses médianes signalées étaient de $10 \mathrm{mg} / \mathrm{kg}$ pour les exacerbations pulmonaires liées à une fibrose kystique, de $7 \mathrm{mg} / \mathrm{kg}$ pour les infections urinaires et de $8 \mathrm{mg} / \mathrm{kg}$ pour les neutropénies fébriles. Trente et un (89\%) des 35 répondants utilisant ces schémas ont indiqué qu’ils surveillaient les taux sériques et 27 (77\%) ont signalé exercer un suivi pour déceler une néphrotoxicité. En ce qui touche au droit de prescrire, 7 (16\%) des 45 répondants ont indiqué que les pharmaciens étaient autorisés à modifier eux-mêmes la posologie dans leurs établissements et des pharmaciens dans 14 (31\%) des 45 établissements étaient autorisés à prescrire des paramètres de surveillance.

Conclusions : Les traitements par aminosides avec administration d'une dose élevée à intervalle prolongé étaient fréquemment utilisés pour les enfants partout au Canada, mais les posologies et les habitudes de surveillance variaient beaucoup. L'information contenue dans la présente 
Can J Hosp Pharm. 2016;69(5):367-75 étude peut servir à faire la comparaison des habitudes au sein d'autres centres à l'échelle du Canada.

Mots clés : pédiatrie, aminosides, gentamicine, tobramycine, dose élevée à intervalle prolongé

\section{INTRODUCTION}

A minoglycosides, including tobramycin and gentamicin, are traditionally administered multiple times daily; however, previous studies have shown that high-dose, extended-interval regimens are as efficacious, potentially safer, and less expensive for both adult and pediatric patients. ${ }^{1-3}$ High-dose, extendedinterval therapy generally refers to administration of the total daily amount of aminoglycoside as one dose, usually every $24 \mathrm{~h}$. Aminoglycosides act by concentration-dependent killing and thus are most effective at concentrations 8-10 times the minimum inhibitory concentration of the bacteria. ${ }^{4,5}$ They exhibit residual bacterial killing after the concentration falls below the minimum inhibitory concentration, a phenomenon known as the post-antibiotic effect. ${ }^{4,6}$ Efficacy is also affected by adaptive resistance, the mechanism by which certain bacteria, including Pseudomonas aeruginosa and Enterobacteriaceae, reduce the uptake and accumulation of aminoglycosides over time. ${ }^{7,8}$ As the serum concentration of antibiotic decreases to an undetectable level, adaptive resistance is inhibited. High-dose, extendedinterval therapy generates a high peak serum concentration for concentration-dependent killing, followed by undetectable trough levels, which allow for the post-antibiotic effect and inhibition of adaptive resistance.

High-dose, extended-interval aminoglycoside therapy may decrease both nephrotoxicity and ototoxicity relative to traditional dosing. It has been suggested that nephrotoxicity is due to increased trough levels, and the incidence of nephrotoxicity in adults has been shown to be greater with multiple daily regimens than with high-dose, extended-interval regiments. ${ }^{9,10}$ In studies involving pediatric patients, the incidence of nephrotoxicity was no different between the multiple daily dosing and high-dose, extended-interval groups ( $0.94 \%$ to $1.6 \%)$, and was less than reported for adult populations with high-dose, extended-interval therapy $(5.5 \%) .{ }^{11-13}$ Ototoxicity is less well understood, but it is usually irreversible and may be related to higher cumulative total exposure. ${ }^{1}$ The reported incidence of ototoxicity with high-dose, extended interval therapy in pediatrics has ranged from $1.88 \%$ to $2.3 \%$, with no significant difference relative to traditional dosing, ${ }^{11,12}$ whereas a meta- analysis of adult patients reported incidence of ototoxicity in the range of $0.4 \%$ to $6.2 \% .{ }^{14}$ Regardless, neither nephrotoxicity nor ototoxicity appears to occur more frequently among pediatric patients receiving high-dose, extended-interval therapy than among patients who receive traditional dosing, rendering these regimens at least as safe.

High-dose, extended-interval regimens may be more costeffective, because they require less effort in preparation and administration, as well as less laboratory analysis (because of the reduced frequency of drug monitoring)..$^{4,11}$ A cost-effectiveness analysis of gentamicin in neonates determined that this approach was superior to traditional dosing because it reduced labour and materials and eliminated monitoring of serum concentration with short courses $(<72 \mathrm{~h}) .{ }^{15}$ This regimen also facilitates outpatient use of aminoglycosides and improves patient convenience. ${ }^{4}$

High-dose, extended-interval therapy for aminoglycosides is not well established for pediatric patients, likely because of substantial variation in dosing, monitoring parameters, and target populations, and its application in studies with small sample sizes. Larger studies, with adequate power to confirm the safety and effectiveness of high-dose, extended-interval aminoglycoside therapy in pediatrics, have recently been published, ${ }^{11-13,16-19}$ but there still is no clear consensus on optimal dosing and monitoring practices. The most recent Cystic Fibrosis Foundation guidelines for pulmonary exacerbations in cystic fibrosis recommend use of high-dose, extended-interval dosing, rather than 3 times daily dosing, for the treatment of acute exacerbation of pulmonary disease (grade $\mathrm{C}$ recommendation, with grade $\mathrm{C}$ being defined as follows: “The Cystic Fibrosis Foundation's Pulmonary Therapies Committee recommends against routinely providing the service. There may be considerations that support providing the service to an individual patient. There is moderate or high certainty that the net benefit is small"). ${ }^{20}$

Use of high-dose, extended-interval aminoglycoside therapy for a variety of pediatric populations is increasing in the United States, ${ }^{21,22}$ although information describing prescribing patterns in Canada is not available. Given that there is no clear best practice for this type of therapy in pediatric patients, determining 
current practice in Canada is an important first step in ensuring provision of optimal care for these patients. In many institutions around the world, pharmacists participate in the management of aminoglycoside therapy for pediatric and adult populations. ${ }^{22,23}$

The purpose of this study was to characterize aminoglycoside prescribing practices for pediatric inpatients across Canada, with a focus on high-dose, extended-interval therapy for tobramycin and gentamicin. The objective was to determine the current practices of Canadian health care delivery organizations with regard to high-dose, extended-interval gentamicin and tobramycin therapy for pediatric inpatients, including indications for use, use in patients with particular comorbidities, dosing and monitoring practices, and the extent of pharmacists' authority to independently dose or monitor aminoglycosides.

\section{METHODS}

This study used a prospective survey methodology. The survey was distributed in March 2015 to pharmacy managers and directors of Canadian health care delivery organizations, including health authorities, health regions, local health integration networks, and individual hospitals, as listed in a database previously compiled by a colleague and used with permission. Our colleague created the database by identifying Canadian health care delivery organizations through web searches, creating a contact list based on health authority and hospital staff listings and his own contacts, and then contacting the health care delivery organizations to identify pharmacy managers or directors. Health care delivery organizations without accessible contact information and those that described themselves as not delivering inpatient pediatric services were excluded from the current study. Potential participants received an initial e-mail outlining the project's purpose, objectives, design, and timeline, as well as a link to the electronic survey. Each recipient was asked to forward the survey to the pharmacist with the greatest experience with the institution's pediatric aminoglycoside practices; for health care organizations with more than one institution, the recipient was asked to limit the invitation to one pharmacist at each institution that might have its own aminoglycoside practices. The purpose of restricting the invitation in this way was to capture a variety of practices or protocols and to minimize duplication. For example, if multiple sites within one health region used the same protocol, the investigators were interested in capturing information about that protocol only once.

The survey was created by the investigators using Fluid Surveys online survey software (FluidSurveys, Ottawa, Ontario). The investigators have expertise in survey methodology, institutional pharmacy practice, pediatrics, and aminoglycosides. The survey was reviewed by 2 pediatric pharmacists at other Canadian institutions, who were asked to assess its clarity, question skip logic, and face validity. The survey consisted of 18 questions with additional subquestions, depending on responses, that collected information on the characteristics of the health care organizations, the clinical contexts (comorbidities) in which high-dose, extended-interval aminoglycoside therapy could be used, empiric dosing, and monitoring parameters, as well as the extent of pharmacists' authority to independently monitor and adjust doses of aminoglycosides at their respective institutions (see Appendix 1, available at www.cjhp-online.ca/index.php/cjhp/ issue/view/117/showToc). The questions and response options in the survey were based on a literature search of studies of high-dose, extended-interval gentamicin and/or tobramycin therapy in pediatrics, as well as local practice and a review of available external protocols for aminoglycosides in pediatrics. The literature search was conducted by the primary investigator (C.R.) and a medical librarian and identified English-language articles in the MEDLINE, Cochrane Library, Embase, and International Pharmaceutical Abstracts databases. The following search terms (including synonyms and related terms) were used: "pediatric", "aminoglycoside", "gentamicin", "tobramycin”, "once daily dosing", "high-dose extended-interval", "pyelonephritis", "urosepsis", "urinary tract infection", "cystic fibrosis", "febrile neutropenia", and "pneumonia". To keep the focus of the survey narrow, studies involving neonates and newborn infants and those investigating amikacin were excluded. In the authors' health region, amikacin is reserved for infections with organisms resistant to both tobramycin and gentamicin, but it is rarely used. Furthermore, no specific questions about critically ill patients were asked, as the local health region did not provide services to this patient population at the time of the survey.

Questions about dose focused on use of the drugs of interest in cystic fibrosis, urinary tract infection, and febrile neutropenia, because the literature review identified these disease states as the ones that have been most studied in pediatric patients. For questions to which respondents could reasonably be expected to have more than one response, respondents were allowed to select all answers that applied to their respective institutions. A free-text box was provided to capture additional responses. None of the questions were mandatory. Respondents were instructed to provide responses referring only to the care of pediatric patients and to exclude any reference to practices for patients in the neonatal intensive care unit. The survey took about $10 \mathrm{~min}$ to complete and was open for responses for 1 month; potential participants received a midpoint reminder via e-mail.

This study was approved on ethical grounds by the Regina Qu'Appelle Health Region Research Ethics Board as REB-14-146.

\section{Statistical Analyses}

Most of the data collected in the survey was categorical in nature, and the descriptive analysis took the form of frequency distributions. For continuous data, the mean and standard deviation were used as summary statistics; the median and 
interquartile range were also presented when significant skew (as determined by the Fisher skewness coefficient) was found. All statistical analyses were performed with SPSS Statistics for Windows software, version 22.0 (released 2013; IBM Corp, Armonk, New York).

\section{RESULTS}

The initial e-mail requesting participation in this survey was sent to pharmacy directors and managers from 104 health regions; 10 of the messages were undeliverable, which left 94 potential participants. A total of 45 pharmacists responded to the survey, for a $48 \%$ response rate. The majority of respondents were from Ontario or Manitoba, and just over half represented multisite organizations. There was a diverse representation of hospital types and pediatric services (Table 1).

A total of 35 respondents (78\%) reported the use of highdose, extended-interval aminoglycoside therapy for pediatric inpatients. Comorbidities, weights, and age limits defining the specific pediatric inpatients for which this therapeutic approach could be used are outlined in Table 2. Several respondents noted that high-dose, extended-interval therapy was their institutions' preferred regimen and that it was used for all patients as clinically

Table 1. Characteristics of Institutional Survey Respondents

\begin{tabular}{|c|c|c|c|c|c|c|c|c|c|c|c|c|c|}
\hline \multirow[b]{2}{*}{ Characteristic } & \multicolumn{11}{|c|}{ Province or Territory; No. of Institutional Respondents } & \multicolumn{2}{|c|}{ Total No. (\%) } \\
\hline & $\mathrm{AB}$ & BC & MB & NB & NL & NS & NT & ON & PE & QC & SK & & \\
\hline No. of respondents & 3 & 2 & 10 & 3 & 1 & 3 & 1 & 11 & 1 & 4 & 6 & 45 & $(100)$ \\
\hline Multisite organizations & 2 & 1 & 5 & 2 & 1 & 2 & 0 & 5 & 0 & 2 & 4 & 24 & $(53)$ \\
\hline \multicolumn{14}{|l|}{ Hospital type } \\
\hline Tertiary & 2 & 1 & 8 & 2 & 0 & 1 & 0 & 6 & 0 & 1 & 3 & 24 & (53) \\
\hline Community & 1 & 0 & 2 & 1 & 1 & 2 & 1 & 3 & 1 & 2 & 4 & 18 & (40) \\
\hline Academic & 0 & 1 & 7 & 1 & 0 & 1 & 0 & 6 & 0 & 1 & 2 & 19 & $(42)$ \\
\hline Pediatric services only & 1 & 0 & 3 & 0 & 0 & 0 & 0 & 5 & 0 & 0 & 0 & 9 & (20) \\
\hline \multicolumn{14}{|l|}{ Size of pediatric services } \\
\hline$<25$ beds & 2 & 2 & 1 & 3 & 0 & 2 & 1 & 2 & 1 & 3 & 4 & 21 & $(47)$ \\
\hline 25-100 beds & 0 & 0 & 3 & 0 & 0 & 0 & 0 & 2 & 0 & 0 & 2 & 7 & (16) \\
\hline$>100$ beds & 1 & 0 & 6 & 0 & 1 & 1 & 0 & 7 & 0 & 1 & 0 & 17 & (38) \\
\hline \multicolumn{14}{|l|}{ Type of pediatric pharmacist services } \\
\hline Clinical (patient-centred) & 0 & 1 & 1 & 1 & 0 & 0 & 0 & 0 & 1 & 0 & 0 & 4 & (9) \\
\hline Distributive & 0 & 0 & 1 & 2 & 0 & 0 & 1 & 0 & 0 & 0 & 0 & 4 & (9) \\
\hline Mixed clinical and distributive & 3 & 1 & 8 & 0 & 1 & 2 & 0 & 11 & 0 & 4 & 6 & 36 & (80) \\
\hline $\begin{array}{l}\text { Using high-dose, extended-interval } \\
\text { therapy in pediatric inpatients }\end{array}$ & 3 & 19 & 2 & 0 & 2 & 1 & 1 & 0 & 1 & 3 & 3 & 35 & (78) \\
\hline
\end{tabular}

\section{Table 2. Criteria for Use of High-Dose, Extended-Interval Aminoglycoside Therapy across Canadian Institutions}

\begin{tabular}{|c|c|}
\hline Criterion & Response $(n=35)$ \\
\hline $\begin{array}{l}\text { Age for first use of HDEl aminoglycoside } \\
\text { therapy (years) (median and IQR) }\end{array}$ & $4(1.25-6.75)$ \\
\hline \multicolumn{2}{|l|}{$\begin{array}{l}\text { Comorbidities with which HDEl aminoglycoside } \\
\text { therapy may be used }\end{array}$} \\
\hline Renal impairment* & $6(17)$ \\
\hline Hearing impairment† & $4(11)$ \\
\hline Pregnancy & $1 \quad(3)$ \\
\hline Ascites & $2(6)$ \\
\hline Severe burns & $3 \quad(9)$ \\
\hline $\begin{array}{l}\text { Body weight of patients for whom HDEI } \\
\text { aminoglycoside therapy may be used (kg) } \\
\text { (median and IQR) }\end{array}$ & $5(5-27.5)$ \\
\hline \multicolumn{2}{|c|}{$\begin{array}{l}\text { HDEI = high-dose, extended-interval; IQR = interquartile range. } \\
\text { *Two respondents specified a specific cut-off value for creatinine clearance } \\
\text { (40 mL/min and } 50 \mathrm{~mL} / \mathrm{min} \text {, respectively). The other respondents did not specify } \\
\text { a cut-off beyond which HDEl aminoglycoside therapy could not be used. } \\
\text { thearing impairment was defined in the survey as known vestibular disease or } \\
\text { clinical hearing loss. }\end{array}$} \\
\hline
\end{tabular}


indicated. Other free-text responses included "empiric or documented infections with gram-negative organisms", "all except synergy [dosing] and surgery", "pneumonia", "dialysis", "meningitis", "high mortality risk", and "occasionally as part of their postoperative prophylactic antibiotics". One respondent noted that the institution switches to high-dose, extendedinterval therapy for outpatient use.

The 35 respondents who indicated that high-dose, extended-interval therapy was used at their institutions were asked about specific doses used for cystic fibrosis, urinary tract infections, and febrile neutropenia. Nineteen (54\%) of these respondents responded to the question, with 15,10 , and 13 providing dosing details for cystic fibrosis, urinary tract infection, and febrile neutropenia, respectively (Table 3). The same 35 respondents were asked which weight calculation was used for high-dose, extended-interval aminoglycoside therapy. There were a total of 46 responses from the 35 respondents, with 27 (77\%) of the 35 indicating that the patient's actual body weight was used (Table 3). Twenty-five of the respondents reported using the same dosing parameters for both gentamicin and tobramycin. For those centres that did not use the same dosing parameters for the 2 drugs, differences were based on indication, age, or a combination of these factors. The following differences were reported: 2 centres used only tobramycin for cystic fibrosis, at doses of $8-10 \mathrm{mg} / \mathrm{kg}$; 1 centre used only gentamicin for urinary tract infection, at doses of $5-8 \mathrm{mg} / \mathrm{kg}$; and 1 centre used only tobramycin for febrile neutropenia, with the dose varying according to age $(10 \mathrm{mg} / \mathrm{kg}$ for patients 6 years of age or younger; $8 \mathrm{mg} / \mathrm{kg}$ for patients older than 6 years of age). The survey did not specifically ask about dosing intervals.

The 35 respondents who reported using high-dose, extended-interval aminoglycosides were asked about monitoring parameters for serum levels and toxicity; $31(89 \%)$ indicated that they routinely monitored serum levels (Table 4). Specific details about peak and trough monitoring parameters are presented in
Table 5 . The 3 respondents who reported using area under the curve measured the first sample $2 \mathrm{~h}(n=1)$ or $3 \mathrm{~h}(n=2)$ after the start of infusion and the second sample $6 \mathrm{~h}(n=3)$ after the start of infusion, targeting $70-100 \mathrm{mg} * \mathrm{~h} / \mathrm{L}(n=2)$ or $70-110 \mathrm{mg}{ }^{*} \mathrm{~h} / \mathrm{L}(n=1)$. These 3 respondents indicated that the area under the curve was measured after 1 day of therapy. With respect to dose adjustments based on monitoring of serum level for all respondents using high-dose, extended-interval aminoglycoside therapy, the responses were varied and included changing the dose or the interval on the basis of individual kinetics or a particular nomogram not specified. The majority of respondents $(n=25)$ used the same monitoring parameters for gentamicin and tobramycin.

Twenty-seven (77\%) of the 35 respondents who reported utilization of high-dose, extended-interval aminoglycoside therapy responded to questions about toxicity monitoring. All of these 27 respondents reported monitoring for nephrotoxicity. Seventeen of the respondents reported monitoring renal panels at various frequencies (daily to weekly, depending on patient population). Eleven (31\%) of the centres reported monitoring for ototoxicity; of these, 8 reported performing objective audiometry, at frequencies ranging from after 14 days of therapy to annually or only if the patient reports symptoms. Five centres reported monitoring for subjective symptoms of ototoxicity (i.e., dizziness, ringing in the ears, difficulty hearing). The timing of symptom assessment varied, ranging from day 0 to day 14 of therapy. Sixteen of the respondents indicated that their respective institutions did not routinely monitor for ototoxicity.

All 45 respondents were asked about pharmacists' authority to independently dose or monitor aminoglycoside therapy in pediatric inpatients, regardless of whether the institution used high-dose, extended-interval therapy. Seven (16\%) indicated that pharmacists were able to independently adjust dosing, and 14 (31\%) reported that pharmacists could independently order monitoring parameters, including serum drug levels $(n=14)$;

Table 3. Dosing Parameters for High-Dose, Extended-Interval Aminoglycoside Therapy across Canadian Institutions

\begin{tabular}{|c|c|}
\hline Aspect of Dosing & Data ( $n=35$ Respondents) \\
\hline Indication & Median dose $(\mathrm{mg} / \mathrm{kg})$ and IQR \\
\hline Cystic fibrosis & $10(10-11.5)$ \\
\hline Urinary tract infection & $7(6-8)$ \\
\hline Febrile neutropenia & $8(7-9)$ \\
\hline Patient weight for dosing* & No. (\%) of Respondents \\
\hline Actual body weight (ABW) & $27(77)$ \\
\hline Desired dosing weight (DDW) & $7 \quad(20)$ \\
\hline ABW when $A B W<D D W$ & 11 (31) \\
\hline $\begin{array}{l}\text { Standard growth chart for percentile, } \\
\text { based on age and height }\end{array}$ & $1 \quad(3)$ \\
\hline $\begin{array}{l}\text { Standard growth chart using 50th } \\
\text { percentile if only age is known }\end{array}$ & $0 \quad(0)$ \\
\hline
\end{tabular}


Table 4. Monitoring Parameters for High-Dose, Extended-Interval Aminoglycoside Therapy across Canadian Institutions

\begin{tabular}{lrr} 
Monitoring Parameter & $\begin{array}{r}\text { No. (\%) of Respondents } \\
(\boldsymbol{n}=35)\end{array}$ \\
\hline Routine monitoring of serum levels & 31 & $(89)$ \\
Monitoring of trough levels only & 10 & $(29)$ \\
Monitoring of peak levels only & 1 & $(3)$ \\
Monitoring of trough and peak levels & 7 & $(20)$ \\
Measurement of area under the curve & 3 & $(9)$ \\
Random sampling (variably timed samples)* & 6 & $(17)$ \\
Hartford nomogram² & 7 & $(20)$ \\
Othert & 9 & $(26)$ \\
\hline${ }^{*}$ One respondent indicated that random samples are drawn at 2 h and 8 h \\
after infusion; other respondents who chose this option did not indicate specific \\
times. \\
tOther responses specified timing of random samples or peaks, different \\
practices for different disease states, and the types of individual kinetics \\
calculated, such as extrapolated peak, drug-free interval, volume of distribution, \\
maximum serum concentration, elimination constant, and half-life.
\end{tabular}

\section{Table 5. Therapeutic Drug Monitoring Parameters for Troughs and Peaks}

\begin{tabular}{|c|c|c|}
\hline Monitoring Parameter & No. $(\%)$ & f Respondents* \\
\hline Troughs & & $n=17$ \\
\hline Timing of trough level & & \\
\hline 0-60 min before infusion & 15 & $(88)$ \\
\hline $18 \mathrm{~h}$ after infusion & 2 & $(12)$ \\
\hline Target (i.e., less than $x$ mg/L) (median and IQR) & 1 & $(0.8-1.25)$ \\
\hline $\begin{array}{l}\text { Day of therapy after which level is measured } \\
\text { (median and IQR) }\end{array}$ & 2.5 & $(2-3)$ \\
\hline Peaks & & $n=8$ \\
\hline Target (mg/L) & & \\
\hline $15-25$ & 3 & (38) \\
\hline $15-30$ & 2 & $(25)$ \\
\hline $25-35$ & 1 & $(12)$ \\
\hline $\begin{array}{l}\text { Day of therapy after which level is measured } \\
\text { (median and IQR) }\end{array}$ & 1.5 & $(1-4.5)$ \\
\hline
\end{tabular}

serum creatinine, with or without blood urea nitrogen $(n=14)$; body weight $(n=9)$; urine output $(n=9)$; complete blood count with differential $(n=4)$; and temperature $(n=1)$.

\section{DISCUSSION}

To the authors' knowledge, this is the first survey of Canadian practices related to high-dose, extended-interval tobramycin and gentamicin therapy in pediatric inpatients. The response rate (48\%) was relatively high; however, throughout the survey there were many sections with missing responses, which decreases the validity of results for those sections. The number of responses from small and large pediatric services aligns with the mix of services provided across Canada, and there was representation from each of the provinces and one territory. Overall, this study shows that practices related to high-dose, extended-interval aminoglycoside therapy in pediatric inpatients vary greatly across Canada with respect to indications, use in patients with certain comorbidities, dosing parameters, and monitoring.

The proportion of respondents who reported using highdose, extended-interval tobramycin or gentamicin for pediatric inpatients $(78 \%)$ falls midway within the range reported from US surveys: $23.1 \%$ in centres treating all disease states ${ }^{22}$ to $94.3 \%$ in cystic fibrosis-accredited care centres. ${ }^{21}$ The comorbidities in which high-dose, extended-interval aminoglycoside therapy could be used were not specified by all respondents, and therefore the results may not accurately reflect true practice. The variation in ages identified by survey respondents aligns with the wide range of ages studied in the literature. A few institutions indicated using high-dose, extended-interval aminoglycoside therapy for patients with pregnancy, ascites, and burns, which differs from routine practice, given that this form of therapy has not been evaluated for these patient populations. ${ }^{1}$ 
Use of high-dose, extended-interval aminoglycoside therapy was commonly reported for disease states beyond cystic fibrosis, urinary tract infection, and febrile neutropenia, including pneumonia, meningitis, and (in some institutions) all infections in which suspected pathogens might be susceptible. There is evidence demonstrating the efficacy and safety of this approach in these additional disease states as mentioned by respondents, ${ }^{19,25-28}$ although the evidence for its use in pediatric patients is more established for the disease states that were specifically questioned.

Dosing practices (as reported by respondents) varied considerably across Canada; however, the most common doses identified for each disease state are supported by the literature. For cystic fibrosis, the most common dose $(10 \mathrm{mg} / \mathrm{kg})$ aligns with the recommended dosage of $10 \mathrm{mg} / \mathrm{kg}$ once daily from the TOPIC study. ${ }^{29}$ In that study, which involved patients older than 5 years with pulmonary exacerbations of cystic fibrosis, this dose of tobramycin was as efficacious as 3 times daily dosing in terms of change in forced expiratory volume in $1 \mathrm{~s}$ and was safer in terms of changes in serum creatinine. The lower doses of 5 to $9 \mathrm{mg} / \mathrm{kg}$ for urinary tract infections and febrile neutropenia found in the current study align with the dosages most commonly reported in the literature: $5 \mathrm{mg} / \mathrm{kg}$ once daily $\mathrm{y}^{19,26,27,30,31}$ and $7-9 \mathrm{mg} / \mathrm{kg}$ once daily, ${ }^{18,19,32-35}$ respectively, depending on the patient's age. Although the current survey did not specifically request dosing intervals, a $24-\mathrm{h}$ interval may be assumed for empiric dosing, as the doses reported by respondents are supported by the once-daily doses found in the literature.

Therapeutic drug monitoring was common, although the monitoring practices and dose adjustments for high-dose, extended-interval aminoglycoside therapy were not consistent across the country. No clear recommendations for drug monitoring have been established for the pediatric population, and each monitoring parameter is supported by the literature to some extent to ensure both efficacy and safety. Increased trough levels have been associated with nephrotoxicity, and monitoring may be useful to ensure that the drug is not accumulating and to measure the drug-free interval. ${ }^{1,9,19,33}$ The measurement of peaks as well as troughs may be used to confirm that the desired ratio of maximum serum concentration to minimum inhibitory concentration $\left(C_{\max }: \mathrm{MIC}\right)$ of $8-10: 1$ is being achieved, to calculate individual kinetics, and to ensure that the drug is not accumulating, although increased peaks have not been associated with nephrotoxicity. ${ }^{1,9,19}$ The one respondent who indicated that only peaks were monitored may have misinterpreted the question, as this is not an appropriate method for monitoring the safety and efficacy of high-dose, extended-interval aminoglycoside therapy. Therapeutic drug monitoring in traditionally dosed aminoglycosides has been associated with reductions in side effects and mortality, and may be cost-effective ${ }^{36}$; however, this approach has not been fully elucidated in high-dose, extended-interval aminoglycoside therapy or in the pediatric population.

There is no clear guidance on optimal monitoring for nephrotoxicity and ototoxicity with aminoglycoside use. The Canadian product monographs for gentamicin and tobramycin suggest monitoring urinalysis, urine output, blood urea nitrogen, and serum creatinine at baseline and periodically throughout therapy. ${ }^{37,38}$ Surveys about high-dose, extended-interval aminoglycoside therapy in pediatric patients in the United States and Australia found that more than $95 \%$ of respondents routinely monitored for nephrotoxicity, with most monitoring serum creatinine weekly according to patient-specific risk factors for nephrotoxicity. ${ }^{21,22,39,40} \mathrm{~A}$ similar situation was seen in the current survey, and although only $77 \%$ of respondents reported routinely monitoring for nephrotoxicity, it is uncertain whether the remaining $23 \%$ actually monitor for this adverse effect: these latter respondents may have chosen not to respond to the question rather than specifying that they do not follow this practice. Routine monitoring for ototoxicity was less commonly reported in the current survey and in other surveys, in which up to half of respondents reported that they did not monitor for ototoxicity. ${ }^{21,39,40}$ This practice may be more relevant for patients with concomitant ototoxic therapies or long-term use of aminoglycosides. . $^{37,38}$

Of the pharmacists responding to the survey, one-third reported being able to independently order monitoring parameters for aminoglycosides in pediatric patients, and 16\% were able to independently adjust aminoglycoside doses. Among institutional respondents to the 2011/2012 Hospital Pharmacy in Canada survey, $55 \%$ reported that pharmacists had prescribing rights approved within their respective hospitals, and among these hospitals with prescribing rights for pharmacists, 59\% reported that pharmacists could independently prescribe for lab tests, and $48 \%$ reported that pharmacists could independently adjust doses. ${ }^{41}$ However, these data are not specific to pediatrics. Prescriptive authority for pharmacists is becoming an integral part of the pharmacy profession and is supported by professional organizations. The Canadian Society of Hospital Pharmacists has stated that "ultimately, pharmacist prescribing improves patient care by improving access to care and using pharmacists to their full scope of practice". ${ }^{42}$ Many studies have demonstrated the beneficial effects of pharmacists' involvement in collaborative drug therapy management in a variety of settings, ${ }^{43}$ including improvements in health care outcomes (such as decreased hearing loss, renal impairment, and mortality), improvements in economic outcomes with pharmacist-managed aminoglycoside or vancomycin therapy, ${ }^{44}$ higher rates of achievement of aminoglycoside-related pharmacokinetic and pharmacodynamic targets, and reductions in length of stay and costs with clinical pharmacist-managed therapeutic drug monitoring of aminoglycoside therapy in pediatric patients with cystic fibrosis. ${ }^{45}$ 
The variable dosing and monitoring practices across Canada that were identified in this survey reflect the variability in practices reported in the literature. No clear best practice has been identified for high-dose, extended-interval aminoglycoside therapy, and each institution may thus be providing this type of therapy in a manner that is optimal for their respective patient populations. Nonetheless, the information gathered in this study can provide valuable insights for practitioners wishing to compare and reflect on their own practices. Ideally, additional studies of high-dose, extended-interval aminoglycoside therapy will be carried out in larger pediatric populations to determine what best practice is, if any.

This survey study had some limitations. First, the questions were based on current practices in the local health authority and may not have been broad enough to obtain complete information about other institutions' practices. Also, some of the responses captured and the small sample sizes throughout the survey reflect variable interpretations of the survey questions. Furthermore, use of a survey to investigate the study question limits the type of data that can be collected and is subject to misunderstanding of the questions. A limitation inherent to survey studies is potential selection bias, whereby individuals who are more interested in or currently participating in the practice of interest may be more likely to respond. Surveys are also subject to data errors due to nonresponses, as the characteristics of participants who choose to respond to a question may be different from the characteristics of those who choose not to respond, which creates bias. Finally, circulating the invitation to participate via e-mail allowed it to be forwarded and answered by unintended respondents. For example, there were 10 responses from Manitoba and only 2 from British Columbia, which is not representative of the pediatric services provided in these provinces.

\section{CONCLUSION}

High-dose, extended-interval aminoglycoside therapy is frequently used for pediatric patients across Canada, although the dosages and monitoring practices varied greatly. The information from this survey study may be used for cross-comparison of practice by other centres across the country.

\section{References}

1. Jenh AM, Tamma PD, Milstone AM. Extended-interval aminoglycoside dosing in pediatrics. Pediatr Infect Dis J. 2011;30(4):338-9.

2. Maglio D, Nightingale $\mathrm{CH}$, Nicolau DP. Extended interval aminoglycoside dosing: from concept to clinic. Int J Antimicrob Agents. 2002;19(4):341-8.

3. Freeman CD, Nicolau DP, Belliveau PP, Nightingale $\mathrm{CH}$. Once-daily dosing of aminoglycosides: review and recommendations for clinical practice. $J$ Antimicrob Chemother. 1997;39(6):677-86.

4. Edson RS, Terrell CL. The aminoglycosides. Mayo Clin Proc. 1999;74(5): 519-28.

5. Kapusnik JE, Hackbarth CJ, Chambers HF, Carpenter T, Sande MA. Single, large, daily dosing versus intermittent dosing of tobramycin for treating experimental Pseudomonas pneumonia. J Infect Dis. 1988;158(1):7-12.
6. Craig WA, Vogelman B. The postantibiotic effect. Ann Intern Med. 1987; 106(6):900-2.

7. Daikos GL, Jackson GG, Lolans VT, Livermore DM. Adaptive resistance to aminoglycoside antibiotics from first-exposure down-regulation.J Infect Dis. 1990;162(2):414-20.

8. Poole K. Aminoglycoside resistance in Pseudomonas aeruginosa. Antimicrob Agents Chemother. 2005;49(2):479-87.

9. Swan SK. Aminoglycoside nephrotoxicity. Semin Nephrol. 1997;17(1):27-33.

10. De Broe ME, Verbist L, Verpooten GA. Influence of dosage schedule on renal cortical accumulation of amikacin and tobramycin in man.J Antimicrob Chemother. 1991;27 Suppl C:41-7.

11. Contopoulos-Ioannidis DG, Giotis ND, Baliatsa DV, Ioannidis JP. Extended-interval aminoglycoside administration for children: a metaanalysis. Pediatrics. 2004;114(1):e111-8.

12. Best EJ, Gazarian M, Cohn R, Wilkinson M, Palasanthiran P. Once-daily gentamicin in infants and children: a prospective cohort study evaluating safety and the role of therapeutic drug monitoring in minimizing toxicity. Pediatr Infect Dis J. 2011;30(10):827-32.

13. Smyth AR, Bhatt J. Once-daily versus multiple-daily dosing with intravenous aminoglycosides for cystic fibrosis. Cochrane Database Syst Rev. 2014;2: CD002009.

14. Munckhof WJ, Grayson ML, Turnidge JD. A meta-analysis of studies on the safety and efficacy of aminoglycosides given either once daily or as divided doses. J Antimicrob Chemother. 1996;37(4):645-63.

15. Thureen PJ, Reiter PD, Gresores A, Stolpman NM, Kawato K, Hall DM. Once- versus twice-daily gentamicin dosing in neonates $>/=34$ weeks' gestation: cost-effectiveness analyses. Pediatrics. 1999;103(3):594-8.

16. Zakova M, Pong S, Trope A, Atenafu EG, Papaioannou V, Bitnun SA, et al. Dose derivation of once-daily dosing guidelines for gentamicin in critically ill pediatric patients. Ther Drug Monit. 2014;36(3):288-94.

17. Sherwin CM. Zobell JT, Stockmann C, McCrory BE, Wisdom M, Young DC, et al. Pharmacokinetic and pharmacodynamic optimisation of intravenous tobramycin dosing among children with cystic fibrosis. $J$ Pharmacokinet Pharmacodyn. 2014;41(1):71.

18. Inparajah M, Wong C, Sibbald C, Boodhan S, Atenafu EG, Naqvi A, et al. Once-daily gentamicin dosing in children with febrile neutropenia resulting from antineoplastic therapy. Pharmacotherapy. 2010;30(1):43-51.

19. McDade EJ, Wagner JL, Moffett BS, Palazzi DL. Once-daily gentamicin dosing in pediatric patients without cystic fibrosis. Pharmacotherapy. 2010; 30(3):248-53.

20. Flume PA, Mogayzel PJ Jr, Robinson KA, Goss CH, Rosenblatt RL, Kuhn RJ, et al.; Clinical Practice Guidelines for Pulmonary Therapies Committee. Cystic fibrosis pulmonary guidelines: treatment of pulmonary exacerbations. Am J Respir Crit Care Med. 2009;180(9):802-8.

21. Prescott WA Jr. National survey of extended-interval aminoglycoside dosing in pediatric cystic fibrosis pulmonary exacerbations.J Pediatr Pharmacol Ther. 2011;16(4):262-9.

22. Chuck SK, Raber SR, Rodvold KA, Areff D. National survey of extendedinterval aminoglycoside dosing. Clin Infect Dis. 2000;30(3):433-9.

23. Barras M, Alraman H, Kirkpatrick CMJ, Harris M, Dakin C, Jess K, et al. Bayesian optimisation of tobramycin dosing in paediatric patients with cystic fibrosis. J Pharm Pract Res. 2011;41(3):183-7.

24. Nicolau DP, Freeman CD, Belliveau PP, Nightingale CH, Ross JW, Quintiliani R. Experience with a once-daily aminoglycoside program administered to 2,184 adult patients. Antimicrob Agents Chemother. 1995; 39(3):650-5.

25. Bass KD, Larkin SE, Paap C, Haase GM. Pharmacokinetics of once-daily gentamicin dosing in pediatric patients. J Pediatr Surg. 1998;33(7):1104-7.

26. Uijtendaal EV, Rademaker CM, Schobben AF, Fleer A, Kramer WL, van Vught AJ, et al. Once-daily versus multiple-daily gentamicin in infants and children. Ther Drug Monit. 2001;23(5):506-13.

27. Tiwari S, Rehan HS, Chandra J, Mathur NN, Singh V. Efficacy and safety of a single daily dose of gentamicin in hospitalized Indian children: a quasi-randomized trial. J Antimicrob Chemother. 2009;64(5):1096-101.

28. Hennig S, Standing JF, Staatz CE, Thomson AH. Population pharmacokinetics of tobramycin in patients with and without cystic fibrosis. Clin Pharmacokinet. 2013;52(4):289-301. 
29. Smyth A, Tan KH, Hyman-Taylor P, Mulheran M, Lewis S, Stableforth D, et al.; TOPIC Study Group. Once versus three-times daily regimens of tobramycin treatment for pulmonary exacerbations of cystic fibrosisthe TOPIC study: a randomised controlled trial. Lancet. 2005;365 (9459):573-8.

30. Chong CY, Tan AS, Ng W, Tan-Kendrick A, Balakrishnan A, Chao SM. Treatment of urinary tract infection with gentamicin once or three times daily. Acta Paediatr. 2003;92(3):291-6.

31. Carapetis JR, Jaquiery AL, Buttery JP, Starr M, Cranswick NE, Kohn S, et al. Randomized, controlled trial comparing once daily and three times daily gentamicin in children with urinary tract infections. Pediatr Infect Dis J. 2001;20(3):240-6

32. Newby B, Prevost D, Lotocka-Reysner H. Assessment of gentamicin $7 \mathrm{mg} / \mathrm{kg}$ once daily for pediatric patients with febrile neutropenia: a pilot project. J Oncol Pharm Pract. 2009;15(4):211-6.

33. Dupuis LL, Sung L, Taylor T, Abdolell M, Allen U, Doyle J, et al. Tobramycin pharmacokinetics in children with febrile neutropenia undergoing stem cell transplantation: once-daily versus thrice-daily administration. Pharmacotherapy. 2004;24(5):564-73.

34. Sung L, Dupuis LL, Bliss B, Taddio A, Abdolell M, Allen U, et al. Randomized controlled trial of once- versus thrice-daily tobramycin in febrile neutropenic children undergoing stem cell transplantation. J Natl Cancer Inst. 2003;95(24):1869-77.

35. Tomlinson RJ, Ronghe M, Goodbourne C, Price C, Lilleyman JS, Das S, et al. Once daily ceftriaxone and gentamicin for the treatment of febrile neutropenia. Arch Dis Child. 1999;80(2):125-31.

36. Touw DJ, Neef C, Thomson AH, Vinks AA; Cost-Effectiveness of Therapeutic Drug Monitoring Committee of the International Association for Therapeutic Drug Monitoring and Clinical Toxicology. Cost-effectiveness of therapeutic drug monitoring: a systematic review. Ther Drug Monit. 2005;27(1):10-7.

37. Gentamicin [CPhA monograph]. In: e-CPS [database on Internet]. Ottawa (ON): Canadian Pharmacists Association; 2015 [updated 2014 Oct; cited 2015 May 28]. Available from: www.e-cps.ca. Also available in hard copy from the publisher.

38. Tobramycin [CPhA monograph]. In: $e-C P S$ [database on Internet]. Ottawa (ON): Canadian Pharmacists Association; 2015 [updated 2011 Nov; cited 2015 May 28]. Available from: www.e-cps.ca. Also available in hard copy from the publisher.

39. Soulsby N, Bell S, Greville H, Doecke C. Intravenous aminoglycoside usage and monitoring of patients with cystic fibrosis in Australia. What's new? Intern Med J. 2009;39(8):527-31.

40. Van Meter DJ, Corriveau M, Ahern JW, Lahiri T. A survey of once-daily dosage tobramycin therapy in patients with cystic fibrosis. Pediatr Pulmonol. 2009;44(4):325-9.

41. Bussières JF. Chapter B: Clinical pharmacy services. In: Babich M, Bornstein C, Bussières JF, Doucette D, Hall KW, Lefebvre P, et al., editors. Hospital pharmacy in Canada 2011/2012 report. Eli Lilly Canada Inc; 2013. pp. 3-16. Available from: www.lillyhospitalsurvey.ca/hpc2/content/2012_report/ chapter_b\%20.pdf
42. Pharmacist Prescribing Task Force. Prescribing by pharmacists: information paper (2009). Can J Hosp Pharm. 2010;63(3):267-74.

43. Hammond RW, Schwartz AH, Campbell MJ, Remington TL, Chuck S, Blair MM, et al.; American College of Clinical Pharmacy Collaborative drug therapy management by pharmacists - 2003. Pharmacotherapy. 2003;23 (9):1210-25.

44. Bond CA, Raehl CL. Clinical and economic outcomes of pharmacistmanaged aminoglycoside or vancomycin therapy. Am J Health Syst Pharm. 2005;62(15):1596-605.

45. Cies JJ, Varlotta L. Clinical pharmacist impact on care, length of stay, and cost in pediatric cystic fibrosis (CF) patients. Pediatr Pulmonol. 2013; 48(12):1190-4.

Caitlin Roy (formerly Strugari), BSP, ACPR, is a Clinical Pharmacist with the Department of Pharmacy Services, Regina Qu'Appelle Health Region, Regina, Saskatchewan.

Carolyn Gray, BSP, ACPR, is Clinical Coordinator with the Department of Pharmacy Services, Regina Qu'Appelle Health Region, Regina, Saskatchewan.

Lisa Ruda, BSP, ACPR, is a Clinical Pharmacist with the Department of Pharmacy Services, Regina Qu'Appelle Health Region, Regina, Saskatchewan.

Ali Bell, MA, MSc, is a Research Scientist with the Department of Research and Health Information Services, Regina Qu'Appelle Health Region, Regina, Saskatchewan.

Jennifer Bolt, BSCPharm, ACPR, PharmD, is Manager of Research and Development with the Department of Pharmacy Services, Regina Qu'Appelle Health Region, Regina, Saskatchewan.

Competing interests: None declared.

\section{Address correspondence to:}

Caitlin Roy

Department of Pharmacy Services

Regina Qu'Appelle Health Region

1440 - 14th Avenue

Regina SK S4P OW5

e-mail: Caitlin.Roy@rqhealth.ca

Funding: None received.

Acknowledgement: The authors would like to thank Peter Loewen, PharmD, for allowing use of the contact list for Canadian pharmacy managers and directors. 